Challenging traditional classroom practices : Swedish pÿteachers interplay with Finnish curriculum materials

\title{
Hemmi, Kirsti
}

2019-05-04

Hemmi , K , Krzywacki , H \& Liljeqvist, Y 2019 , ' Challenging traditional classroom practices pÿ: Swedish teachers interplay with Finnish curriculum materials ' , Journal of Curriculum Studies , vol. 51 , no. 3 , pp. 342-361 . https://doi.org/10.1080/00220272.2018.1479449

http://hdl.handle.net/10138/308048

https://doi.org/10.1080/00220272.2018.1479449

acceptedVersion

Downloaded from Helda, University of Helsinki institutional repository.

This is an electronic reprint of the original article.

This reprint may differ from the original in pagination and typographic detail.

Please cite the original version. 
The following is a pre-publication version of Hemmi, K., Krzywacki, H., \& Liljekvist, Y. (2018). Hemmi, K., Krzywacki, H., \& Liljekvist, Y. (2018). Challenging traditional classroom practices: Swedish teachers' interplay with Finnish curriculum materials. Journal of Curriculum Studies, 1-20. Published online 08 May 2017, doi.org/10.1080/00220272.2018.1479449

Page numbers will not match those of the published version. 


\title{
Challenging traditional classroom practices: Swedish teachers' interplay with Finnish curriculum materials
}

\author{
In the current paper, we present an analysis of a case study in which we have \\ followed Swedish primary teachers who voluntarily began using translated \\ Finnish curriculum materials, i.e. a textbook and teacher guide, in order to reform \\ their mathematics teaching. The multi-faceted data, consisting of questionnaires, \\ interviews, protocols from collegial meetings, and classroom observations, were \\ gathered during the period 2010-2014. The analysis of the interplay within this \\ cross-cultural setting reveals the special characteristics and the challenges \\ existing in practice. Both the experienced and inexperienced teachers offloaded a \\ great deal of their agency to the materials in order to become familiar with the \\ ideas they mediated. Yet, the lack of a clear rationale behind the organization of \\ the materials, as well as the suggested activities connected to taken-for-granted \\ features of the Finnish teaching tradition, made fruitful interaction problematic. \\ The changes teachers made in their classroom practice were tightly connected to \\ the support offered in the materials, without which the teachers abandoned their \\ new classroom patterns. Based on the results of this study, we suggest a number \\ of general aspects that we regard as important to consider when implementing \\ curriculum materials developed within another cultural-educational context.
}

Keywords: curriculum materials; primary teachers; primary mathematics; crosscultural studies; professional development

\section{Introduction}

Scholars of mathematics education have developed mathematics teaching theories that typically explain teachers' classroom practices with reference to their cognitive traits, such as their mathematical knowledge for teaching (e.g. Hill \& Charalambous, 2012) or their beliefs (e.g. Leder, Pehkonen \& Törner, 2002). Recently, theoretical elaborations and empirical studies emphasizing the role of cultural tools and specific contexts in establishing classroom practices have also begun to catch the attention of researchers (Hill \& Charalambous, 2012; Brown, 2009; Herbel-Eisenmann, Lubienski \& Id-Deen, 2006; Stein \& Kim, 2009). Typically, tools such as textbooks and teacher guides are major resources for teachers when establishing teaching practices and, as such, may both afford and constrain teachers’ actions (Brown, 2009; Remillard, 2005).

Researchers have recently begun theorizing about the interaction between teachers and curriculum materials (Brown, 2009; Remillard, 2005), emphasizing that curriculum artefacts influence teachers' plans and actions, while teachers mobilize curriculum artefacts in various ways depending on, for example, their previous experience and views on good teaching. This qualitative multiple case study contributes to an effort that has not yet been addressed, that is, investigating how the teacher-curriculum material relationship reflects existing cultural teaching norms (Stigler \& Hiebert, 2000).

Swedish curriculum materials seem to have been traditionally developed to support mathematics classrooms in which students work individually with their textbooks and teachers behave more reactively with individual students regarding the problems they are working on, rather than proactively with the whole group (Boesen et al., 2014; Hemmi \& Ryve, 2015b). While there have been several attempts by the Swedish government and school agencies to change this teaching tradition through a national core curriculum and various development initiatives, there has been no strong national movement to reform and develop the curriculum materials in Sweden. 
Nevertheless, Swedish teachers are searching for ways to change the way they design and enact mathematics teaching; they wish to include more communication and variation in their methods, in line with the ethos of the reformed national curriculum implemented in 2008-2011. Recently, for example, there has been a growing interest in applying Finnish curriculum materials in Swedish schools.

Finland is a neighboring country, but in contrast to Swedish students' learning outcomes in mathematics, Finnish students' results have been relatively good (e.g. OECD, 2013). Steering documents are very general in both countries (Hemmi, Lepik, \& Viholainen, 2013a), and teachers can choose the materials they want to use quite autonomously. The curriculum materials in both countries are commercially produced, and there is no national control over them. It is worth noticing that it is the teachers' responsibility to choose such material and utilise it in the classroom in a way that helps students to progress in line with the principles of the national core curriculum. Finland, in contrast to Sweden, has a rather long tradition (since the 1980s) of producing comprehensive teacher guides for Grades 1-6, written by teams of teachers and other experts such as university lecturers working within teacher education. However, the use of curriculum materials produced within another educational context may generate various issues. Teachers' professional identities are aligned with the pedagogical traditions of their country, comprising a characteristic set of lessons and lesson scripts as well as pedagogical strategies that appear to be routine or even unconscious for most teachers (Andrews, 2007).

The aim of the present study is to enhance our understanding of the interplay between teachers and mathematics curriculum materials by investigating the cases of Swedish teachers working with Finnish curriculum materials (FCM). The interplay between a teacher and curriculum materials is embedded in a context that highlights special features of this interplay and, at the same time, reveals invisible traditions of the two countries (e.g. Stigler \& Hiebert, 2000). The study design provides a special intercultural setting, where the use of the materials representing another education culture challenges existing practice. In particular, we shed light on the possible conflicts in the interplay created by the differences between the Swedish traditions the teachers are a part of and the Finnish traditions reflected in the FCM. The research question guiding this study is:

- What is the nature of the interplay between teachers and curriculum materials when Swedish teachers start using Finnish curriculum materials in their classroom practices?

Below, we first elaborate on the relevant literature on the multifaceted interplay between a teacher and curriculum materials. Second, we describe the methodology of the study, including the differences between the Swedish and Finnish teaching traditions as reflected in the curriculum materials. Third, we characterize the Swedish teachers' interplay with the FCM according to the main themes that were developed from the data analysis. We then discuss the results, both in the light of recent research as well as against the background of the teaching traditions of the two countries. We conclude by discussing some general aspects we deem important to consider when implementing curriculum materials in a cross-cultural setting, and outlining a lesson that can be learnt from this special case study. 


\section{Relevant literature}

The interplay between teachers and curriculum materials is shaped by several influential factors, both related to the individual characteristics of teachers and curriculum materials and the educational context. We consider social practice and norms as well as individual factors essential for discussing the teacher-curriculum relationship.

\section{Teacher-curriculum relationship}

The relationship between teachers and curriculum materials has been examined using several theoretical frameworks (Remillard, 2005; Brown, 2009; Remillard \& Bryans, 2004). Our work is embedded in sociocultural theories on the role of artefacts (physical and intellectual tools; in our case curriculum materials) as extensions of human capacities (e.g. Wertsch, 1991). We draw especially on Brown's (2009) model of the teacher-curriculum relationship, and in line with Wertsch (1991), recognize the impact artefacts may have on activities. The relationship between a teacher and curriculum materials is influenced by various individual factors, such as the teacher's knowledge, beliefs and goals, perceptions of the curriculum and students, tolerance for discomfort, as well as experience and professional identity (e.g. Remillard, 2005; Remillard \& Bryans, 2004). A number of studies show that, depending on the character of the materials and how teachers relate to and interact with them, the materials can both afford and constrain the teachers' actions in mathematics classrooms (e.g. Brown, 2009). The organization, the nature of the students' tasks, and the embedded support of the materials interact with teachers, not only as individuals but also as members of social networks (Stein \& Kim, 2009).

McClain, Zhao, Visnovska, and Bowen (2009) identify teachers’ instructional reality, agency, and professional status as important factors when describing the teacher-tool relationship. This is vital for our study because we approach the interplay from a cross-cultural perspective and focus on teachers as being part of the social practices embedded in certain cultural norms (cf. Stigler \& Hiebert, 2000). Curriculum materials are produced within certain educational traditions and are shaped by national perspectives on education as well as on the specific school subjects (cf. Andrews, 2007). Thus, there are significant differences in mathematics curriculum materials in different countries and a special challenge in adapting new ways of acting as a teacher in our study could be that the materials are produced within another teaching tradition. Little is known about what happens when teachers apply materials produced in another cultural context. Our study aims particularly to fill this gap.

Brown (2009) argues that teachers' interactions with instructional materials can be conceptualized in terms of different degrees of 'artefact appropriation'-offloading, adapting, and improvising. For example, when using curriculum materials in a literal manner and following the materials as closely as possible, a teacher offloads a large degree of agency for guiding instructional activity onto the materials. When improvising, a teacher mobilizes other resources, for example her own experience, with minimal reliance on the materials, and the agency is largely shifted to the teacher. When adapting, a teacher combines the materials with his/her personal resources and balances the agency between teacher and materials. Even if these notions take no stand on which way is better, teachers associate judgment and values with how they use materials. For example, Pehkonen (2007) has found that teachers felt they had 'given up a part of their professional competence to the textbook authors' (p. 65), despite the fact that the materials were considered to be of good quality. Teachers even felt guilty relying on the materials instead of on their own planning. 
Further, Kauffman (2002) finds the following themes important to consider when examining beginning teachers' experience of curriculum materials: 1) efficacy, or teachers' perception of the instructional effectiveness of the materials; 2) ease of use, meaning the extent to which the materials alleviate or exacerbate the demands of planning and teaching mathematics; and 3) agency, the extent to which teachers feel they themselves choose what to teach and how to teach it. Christou, Eliophotou Menon, and Philippou (2009) add anxiety to this list of themes. This refers to teachers' worries concerning the organization of their work and the correspondence of their teaching with the demands of national goals and tests. These notions are connected to teachers' professional identities being aligned with the pedagogical traditions in their country (e.g. Andrews, 2007). Our study sheds light on how these traditions affect the interplay between teachers and curriculum materials.

\section{Curriculum materials as a tool for educational reform}

In educational policies, curriculum materials are often designed to support reform (Cohen, 1990; Taylor, 2013), but studies have shown that teachers use tools in ways that harmonize with current practices rather than change the practices. For example, the findings on policy implementation indicate that teachers often assimilate new curricular materials into their current instructional practices rather than reorganize the way they teach as envisioned by those who developed the materials (e.g. Remillard, 2005; Spillane, 1999). Teachers change the materials' intended plans by adding their own ideas, modifying existing structures, or omitting parts that are uninteresting to them, beyond their own capacities, or beyond their students' capabilities (Taylor, 2013). Some studies indicate that inexperienced teachers are the most likely to fully utilize all the reform-based curriculum resources (Remillard \& Bryans, 2004).

There has been a shift in this research field from focusing on the curriculum materials as a way to influence student learning (e.g. Stein, Remillard \& Smith, 2007) toward the development of supportive and even educative curriculum materials for teachers (e.g. Davis \& Krajcik, 2005; Remillard \& Bryans, 2004). The educative nature of the curriculum material is related to the way the process of implementing the curriculum is encompassed. In designing such tools, as Cobb and Jackson (2012) suggest, it is important to assure the usability of the materials; for this to happen, the tools must be easy to access and, at the same time, harmonize with the planned reorganization of practices. The potential of curriculum materials in developing mathematics teachers' knowledge and teaching skills has been identified by several researchers (Ball \& Cohen, 1996; Collopy, 2003; Pehkonen, 2007; Remillard \& Bryans, 2004). If the material is intended to enhance teacher learning, rationales behind the suggested activities play an important role and thus need to be explicated and available to teachers (Davis \& Krajcik, 2005; Brown, 2009).

\section{Methodology}

The study uses a qualitative case study approach (based on Stake 2005), which facilitates our understanding of the interplay between teachers and curriculum materials in a special cultural setting. We engage with a broad open approach to capture all the possible aspects of this interplay, and in practice, the data is based on the insights that various data sources provide us, through the lenses of both individual and collective cases. The outline of the main differences between the Swedish and Finnish classroom cultures, and how the curriculum materials reflect the respective educational culture of each country set a basis for interpretation of the study. 
Finnish and Swedish teaching traditions reflected in curriculum materials

The national core curriculum, in both Sweden and Finland, sets a general outline for school education without defining any explicit learning goals for each school year. The mathematical content for the first school years is quite similar in the two countries' national curricula. However, the Finnish curriculum addresses more the development of students' understanding of mathematical connections than does the Swedish (Hemmi, Lepik \& Viholainen, 2013).

As mentioned above, a common way of working in mathematics classrooms in Sweden has been to let students work with textbook tasks at their own pace (Boesen et al., 2014). Therefore, contrary to the FCM, the Swedish curriculum materials do not typically focus on planning and enacting specific lessons (Hemmi, Koljonen, Hoelgaard, Ahl \& Ryve, 2013). Instead, students' textbooks have been created to facilitate students' individual work and, thus, teacher guides have not played a significant role in Swedish teachers' work (Jablonka \& Johansson, 2011). Contrary to the Swedish tradition, it has been common in Finland to keep the whole class in the same phase while supporting struggling students and offering challenges to those who can work with problems of above-average difficulty (Hemmi \& Ryve, 2015a, 2015b). The organization and content of the FCM aim to facilitate such a working manner. The FCM also include material for checking the correctness of the solutions, as it is common to let Finnish students themselves check the correctness of solutions even in the early grades. In this way, students get immediate feedback and teachers save their time for other things, such as supporting individual students according to their needs. In the Swedish tradition, teachers preferably collect the textbooks once or twice a month and mark the incorrect solutions, especially at primary level.

Recent analyses of the most commonly used Finnish teacher guides (Hemmi, Krzywacki \& Koljonen, 2017) show that the FCM in focus in this study follows the same pattern as the other three Finnish teacher guides. The recurring activities and routines found in the teacher guides have previously been connected to a specific cultural script of Finnish mathematics teaching (Hemmi \& Ryve, 2015a, 2015b). For example, for every lesson, there are suggestions for mental arithmetic activities intended to facilitate formative assessment, students' reflection on their own learning, and the discussion of various strategies. There are also ideas for problem-solving activities, concrete models, materials for differentiation and assessment of teaching, and homework assignments for every lesson. The Finnish tradition of giving homework is connected to the idea of equity, in that all students are expected to manage their assignments regardless of whether they have someone to help them at home. It is also conceived of as a part of effective mathematics teaching and formative assessment by Finnish teacher educators (Hemmi \& Ryve, 2015b). Traditionally, all Finnish mathematics textbook series (Grades 1-6), like the FCM, have included concrete materials as a special resource for teaching and learning for some two decades in answer to the demands of the national mathematics curriculum (Hemmi, et al., 2017). The curriculum materials in focus in the present study (FCM) had been translated from Finnish into Swedish ${ }^{1}$ by the time the Swedish teachers started using it. During data collection, the FCM was also purchased by a Swedish publishing house, which then made the materials available on the Swedish market. We followed this process

\footnotetext{
${ }^{1}$ There is a Swedish-speaking minority (about 5.3\% of the population) in Finland, and they have a right to education at all levels in their mother tongue.
} 
systematically, and recorded the character of the changes that were made to adapt the materials to the Swedish classroom culture during the data collection. We discuss these changes in relation to the results regarding the teachers' interplay with the materials.

\section{The data collection}

The data for this qualitative study consisting of multiple cases were collected in the period 2010-2014, mainly from 12 teachers in three different schools and additionally from two collegial meetings (CM) in which 33 teachers from various schools participated (see Table 1). The common feature of all cases was that the participants were involved in in-service training in professional development conducted in cooperation with the university and that all of them started using the translated FCM-a textbook and teacher guide-voluntarily in their work. The decision to start voluntarily using the FCM was because the Finnish material was available for testing something new. The teachers' teaching experience varied and they taught Grades 1-4. Typically, teachers follow the same students from one grade level to another. The three schools where the main data were gathered varied with regard to the students' socio-economic backgrounds and the proportion of students with an immigrant background.

The data collection was based on various methods including interviews with individuals and groups of teachers focusing on specific themes, questionnaires, classroom observations and recordings of the teachers' collegial meetings. In each case, the data gathering started during the first year of using the FCM with a wide prequestionnaire on their working practices in mathematics and their relation to the curriculum materials (see Appendix 1). The notions brought up in both the questionnaire and the first interviews influenced the following phases of the data gathering process. Table 1 illustrates the multifaceted process of data collection that enables us to examine the complex teacher-curriculum interplay in a special crosscultural setting. following:

Further information about the settings of data gathering is given in the School 1 (S1): The data gathering started in 2010 with six cases of primary teachers using Swedish curriculum materials. They responded to a questionnaire in which the special interest was their experience of and the support provided by the previous curriculum materials, differentiation in their classes, the role of homework, and the use of concrete materials in their teaching. Three of them (T1, T2 and T3) began using the FCM, at the time in Grades 1 and 2. During the first academic year, 2010-2011, four interviews (audiotaped), combined with classroom observations, were conducted with the three teachers. The interviews were thematic and sensitive to what the teachers themselves wanted to discuss about their experiences. However, the focus was mostly on the teachers' relation to and use of the FCM, probing especially for differentiation, homework and which activities in the FCM the teachers were willing to apply in their lessons and why. Moreover, all teachers from Grades 1-5 participated in two collegial meetings, in which discussion themes were derived from the issues important to all the teachers. For example, teachers compared the tasks in the FCM with tasks of the 
national examinations. The focus of classroom observations was on the teachers' use of the FCM in relation to the activities carried out in the classroom. The first author took notes at the collegial meetings and observed the lessons. Further, the data gathering in School 1 continued with follow-ups until 2014. Two more primary teachers started using the FCM in the following academic year, 2011-2012. The lessons of each teacher were observed and the following thematic discussions were recorded. Moreover, a meeting at which the teachers worked on their year plans was documented. Table 1.

Data collection of multiple cases in 2010-2014

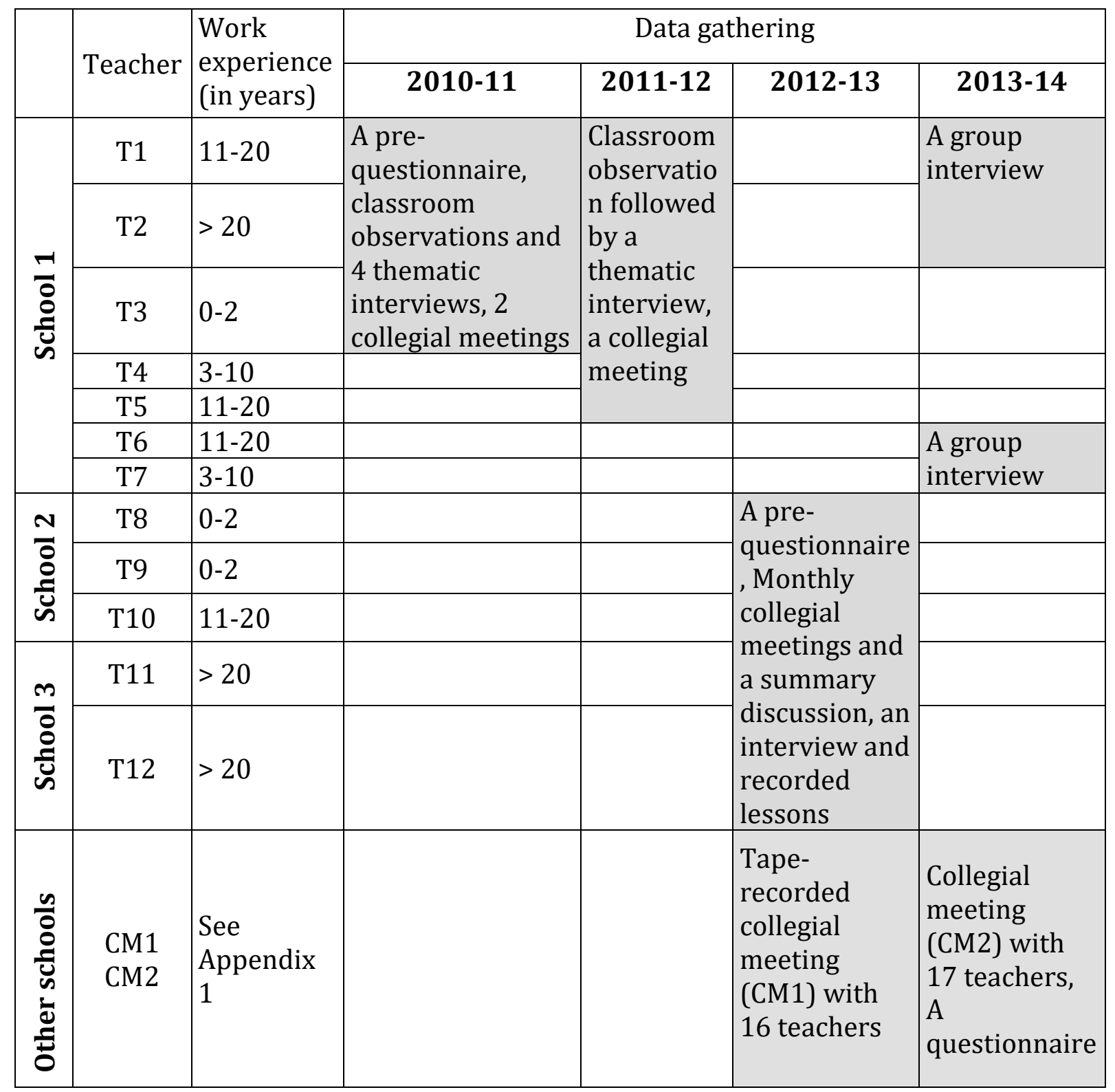

During the third academic year, 2012-2013, the teachers continued using the FCM, but no data were gathered. The final phase of data gathering in School 1 took place in 2014, when a group interview with four teachers (T1, T2, T6, T7) was 
conducted and recorded. It is noteworthy that all the teachers had changed to newly produced Swedish materials in autumn 2013 after having used the Finnish material for one to three years. They had made the switch for organizational reasons, for example to harmonize the range of learning materials used in the same school, but this change provided a fruitful condition for our research.

Schools 2 (S2) and School 3 (S3): The data were gathered from five primary teachers who started working with the FCM in 2012-2013, and who participated in a development project, Count on Västerås, in collaboration with partners representing the municipality and university researchers (see Ryve \& Hemmi, 2017). We followed the work of these teachers closely through monthly collegial meetings that were mainly documented in field notes, discussions about plans for teaching sequence and individual lessons as well as videotaped lessons. We also documented a summary discussion with all teachers from both schools, where they shared their experiences of working with different curriculum materials. Additionally, the five teachers took part in an individual interview focusing especially on the use of the FCM at least once during the research period.

In addition to the multiple cases in Schools 1-3, we gathered some augmenting data from two collegial meetings (cases CM1 and CM2, Table 1) with teachers who had recently started working with the FCM in 2013-2014 and who wanted to share their experience with others and learn more about the rationale behind the FCM. The first meeting with the 16 teachers from various schools (CM1) was audiotaped. The 17 teachers attending the second meeting (CM2) answered a questionnaire that consisted of both open and closed questions based on themes that had emerged from the initial data analyses of the first cases.

When they started working with the FCM, the teachers representing Schools 1-3 received a brief overview of the main differences between Finnish and Swedish mathematics classroom culture, especially concerning homework, assessment, and the differentiation of teaching, whereas the teachers participating in the two collegial meetings (CM1 and CM2) had not received any additional information prior to the meetings where we gathered the data.

\section{Data analysis}

The data analysis of our multiple case study was carried out partly alongside the data gathering process, and at first the aim was to achieve data reduction in order to ensure it was comprehensible and focused on the themes related to the use of curriculum materials. In practice, the initial data analysis started already during the first year with the whole data corpus from School 1. In this phase, notes were made and some initial ideas for sub-themes were noted. An open iterative approach and a thematic inductive analysis were used during the data analysis process. The themes were identified on a semantic level (see Braun \& Clarke, 2006). We started relating our findings to research literature on the teacher-curriculum relationship in parallel with the data gathering and analyses.

The process of more systematically generating the themes and sub-themes started after the transcription of the audiotaped data from all three schools and the first collegial meeting (CM1, 2013). This work was based on the identification of various themes concerning the teachers' interplay with the FCM. The coding was done with the help of NVivo software. In this phase, working themes were written down while searching for the initial sub-themes. Table 2 provides an example of the data analysis process and the initial themes that emerged during this phase. 
Table 2. An example of organizing the data in preliminary themes and sub-themes

The data was divided into units of meaning first and some notions and working themes were written down while exploring the sub-themes.

\begin{tabular}{|c|c|c|c|}
\hline N:o & Excerpt & $\begin{array}{c}\text { Preliminary } \\
\text { themes }\end{array}$ & Sub-theme \\
\hline $\begin{array}{l}\text { Teacher } 8 \text { - } \\
\text { S2, } 2012\end{array}$ & $\begin{array}{l}\text { I think the book itself, } \\
\text { the central content and } \\
\text { the lesson plans, I take } \\
\text { everything as suggested } \\
\text { and it's super. }\end{array}$ & $\begin{array}{l}\text { using the teacher } \\
\text { guide } \\
\text { trust on the material }\end{array}$ & \multirow{4}{*}{$\begin{array}{l}\text { Fidelity to } \\
\text { the material. }\end{array}$} \\
\hline $\begin{array}{l}\text { Teacher 6 - } \\
\text { S1, } 2014\end{array}$ & $\begin{array}{l}\text { I've been lousy at } \\
\text { reading teacher guides, I } \\
\text { think with this material } \\
\text { it's the first time I } \\
\text { started thinking it was } \\
\text { interesting to use the } \\
\text { ideas, don't ask me why. }\end{array}$ & $\begin{array}{l}\text { change the way of } \\
\text { using teacher } \\
\text { guides }\end{array}$ & \\
\hline $\begin{array}{l}\text { Teacher at } \\
\text { CM1, } 2013\end{array}$ & $\begin{array}{l}\text { I think it [the teacher } \\
\text { guide] is good; there are } \\
\text { even suggestions for } \\
\text { what to write on the } \\
\text { board. }\end{array}$ & $\begin{array}{l}\text { added value of the } \\
\text { teacher guide }\end{array}$ & \\
\hline $\begin{array}{l}\text { Teacher11 } \\
\text { - S3, } 2012\end{array}$ & $\begin{array}{l}\text { I want to follow this } \\
\text { carefully ... I feel } \\
\text { so...It's also a way to } \\
\text { get to know the } \\
\text { materials; next time } \\
\text { there might be more } \\
\text { variation - you learn all } \\
\text { the time }\end{array}$ & $\begin{array}{l}\text { following the } \\
\text { suggested ideas in } \\
\text { the teacher guide } \\
\text { teacher guide as a } \\
\text { source for learning }\end{array}$ & \\
\hline
\end{tabular}

The protocols from the observations of lessons and collegial meetings were used to triangulate the initial findings (cf. Stake, 2005). For example, the sub-theme of fidelity could also be identified in the observations of lessons and in the collegiate meetings.

In this phase, the second author was involved in the study, which made it possible to test the first author's interpretations of the data and formulate the unambiguous labels given to each theme. In the first phase of the analysis, we found the following themes relevant: Teachers as users of curriculum materials; Mathematical content and learning of mathematics; and Organization of mathematics teaching (Table 3) (see also Hemmi \& Krzywacki, 2014). 
Table 3. Modification of the themes alongside with the data analysis

Initial themes with sub-themes

\begin{tabular}{|c|c|c|}
\hline $\begin{array}{l}\text { Teachers as users of } \\
\text { curriculum materials }\end{array}$ & $\begin{array}{l}\text { Presentation of the } \\
\text { mathematical content }\end{array}$ & $\begin{array}{l}\text { Organization of } \\
\text { mathematics teaching }\end{array}$ \\
\hline $\begin{array}{l}\text { - Fidelity to the } \\
\text { material } \\
\text { - Adaptation and } \\
\text { adoption } \\
\text { - Usability of the } \\
\text { material }\end{array}$ & 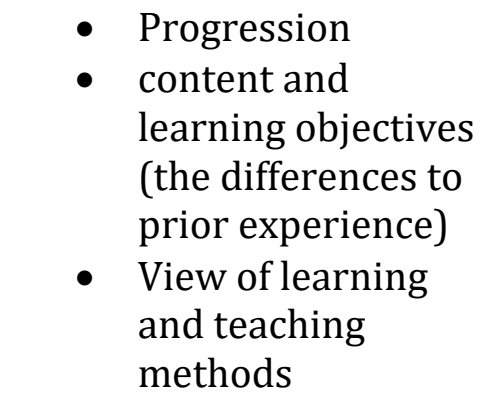 & 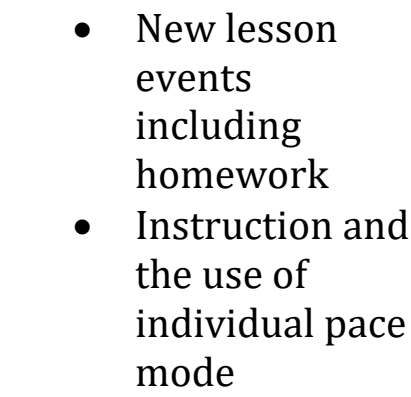 \\
\hline
\end{tabular}

The final themes with sub-themes

\begin{tabular}{|c|c|c|}
\hline $\begin{array}{l}\text { Teachers as users of } \\
\text { curriculum materials }\end{array}$ & $\begin{array}{l}\text { Views on mathematics } \\
\text { education }\end{array}$ & $\begin{array}{l}\text { Lesson scripts and } \\
\text { pedagogical flow }\end{array}$ \\
\hline $\begin{array}{l}\text { - Fidelity to the } \\
\text { material } \\
\text { - Adapting and } \\
\text { improvising } \\
\text { - Usability of the } \\
\text { material }\end{array}$ & $\begin{array}{ll}\text { - } & \text { Progression } \\
\text { - } & \text { View of learning } \\
\text { and teaching } \\
\text { methods } \\
\text { - } \\
\text { Mathematical } \\
\text { language and } \\
\text { structure }\end{array}$ & $\begin{array}{ll}\text { - } & \text { Considering } \\
\text { different } \\
\text { learners } \\
\text { - } & \text { New lesson } \\
\text { events } \\
\text { - } \\
\text { Assessment }\end{array}$ \\
\hline
\end{tabular}

The main findings obtained up to this point were triangulated against the experiences of the teachers who participated in the collegial meeting (CM2) in 2014. In practice, some open questions were formulated concerning fidelity related to the use of the FCM, experience of usability, and organization of teaching connected to differentiation, assessment and homework.

When all the data had been analysed the final organization and the labelling of the subthemes comprising the main themes were refined. In Table 3, both the initial and final themes as well as sub-themes are presented. For example, the final version of the theme labelled as "Views on mathematics education" also covers notions about teaching methods and pedagogical approaches in mathematics classrooms when compared to the initial theme. The theme on "Lesson scripts and pedagogical flow" was reshaped by sub-themes about differentiation and assessment in relation to curriculum materials and their use instead of focusing on the organization of mathematics teaching in general. The themes are not exclusive, in the sense that certain units were categorized into more than just one theme. 
When presenting the results, we follow the structure of the final themes and subthemes, and offer extracts from our data in order to make the data analyses and our interpretations transparent.

\section{Trustworthiness of the study}

In cross-cultural studies, it is important that there are both outsiders and insiders on the research team (e.g. Clarke, 2013), which was the case in our research group. The data analysis was conducted in Swedish. We had also had long-term contact with the area of research as well as practical knowledge of the school systems of both countries (Stake, 2005). The data gathering procedure varied among the different schools throughout the research process due to the emergent character of the study. Our research is based on various cases that were analysed both individually (generalization within the case, cf. Huberman \& Miles, 1994) and across the multiple cases (generalisation between the cases), and thus, served the possibility to understand the authenticity of the phenomenon. We even confirmed our initial themes of the analysis in the later rounds of data gathering. Still, the initial themes related to working practices in mathematics and teachers' relations to the curriculum materials were focused on during the entire data collection. In practice, the study approach was somewhat modified on the grounds of the initial findings. However, the quality of the data was hardly affected due to the open approach of our multiple case study focusing on complex cross-cultural phenomena. The initial findings showed that the multifaceted data hardly provides us with tools for building up a systematic model that would present the way different factors relate to each other in the cross-cultural interplay in this context. According to our understanding, it allows us instead to build up a wide understanding of the nature and process of the cross-cultural interplay between teachers and curriculum materials. We have strengthened the transferability of our research by describing the features of both education contexts and by selecting the cases that reveal relevant experience of the curriculum materials use in a specific setting.

\section{Results}

We portray the Swedish teachers' interplay with the FCM through three main themes, created during the data analysis, that enhance our understanding of the nature of the teacher-curriculum interplay within this special cross-cultural setting. The results are exemplified with extracts from various cases.

\section{Teachers as users of curriculum materials}

The teachers reflected on using the curriculum materials from various perspectives, namely in terms of fidelity to the material, aspects related to improvising and adapting it, usability of the FCM, and teacher learning.

Fidelity to the material. The teachers in our study began using the FCM intensively by familiarizing themselves with it and following the teacher guide. It was quite amazing how strongly the teachers dedicated themselves to the new curriculum materials.

I think the book itself, the central content and the lesson plans, I take everything as suggested and it's super. (T8 - S2, 2012) 
This differs from their previous practice with Swedish materials. As the extract above shows, the teachers used the FCM as their main resource in designing and enacting their teaching. They admitted relying more on the Finnish teacher guides than the Swedish ones:

I've never used a teacher guide as much as now... before I just 'shut' it [the guide] - 'no I won't look at this'. (Teacher at CM1, 2013)

I've been lousy at reading teacher guides, I think with this material it's the first time I started thinking it was interesting to use the ideas, don't ask me why. (T6 S1, 2014)

The analysis of the teachers' responses to the pre-questionnaire (Appendix 1) also shows that they previously used the Swedish curriculum materials as only one option among other resources. It was common to improvise much more in the classroom, for example, basing their teaching on students' questions. The teachers' heavy reliance on the FCM was also confirmed by 17 teachers' responses to the questionnaire at the collegial meeting (CM 2, 2014). All but one of them either strictly followed the instructions in the materials or only slightly adapted them in their practice (Appendix 2).

Many teachers found the explicit parts of the teacher guides to be helpful and inspiring, regardless of the length of their teaching experience. For instance, they used the ready-made questions to investigate the textbook picture along with their students and followed the guidelines for what to write on the board:

I think it [the teacher guide] is good; there are even suggestions for what to write on the board. (Teacher at CM1, 2013)

The teachers with more teaching experience wanted to carefully follow the materials in order to become familiar with them and understand the ideas presented about designing mathematics instruction in a totally new manner. A desire to learn to work differently in mathematics classrooms was highlighted:

I want to follow this carefully ... I feel so...It's also a way to get to know the materials; next time there might be more variation - you learn all the time. (T11 S3, 2012)

Teachers' year plans and the documented lessons showed that they followed the materials' structure and instruction quite closely.

Adapting and improvising. Nevertheless, teachers with differing lengths of teaching experience also incorporated their own ideas into the suggested lesson activities, and hence both improvised using their own resources and adapted the ideas of the FCM. For example, some teachers modified their storytelling in order to harmonize the lesson theme with other subjects, or invented their own stories inspired by the FCM.

Some experienced teachers viewed the FCM, with its explicit ideas for lesson activities, as particularly appropriate for teachers who lack knowledge in mathematics education. An intensive use of the teacher guide during a lesson could be regarded as a token of a teacher's lack of experience and personal resources: 
One does not have to take [everything from the guide] ... but I see a colleague of mine who hasn't had much mathematics in her education; she gets a lot of support from the guide. I see that she has it open like this on her desk when she's teaching. (T2 - S1, 2011)

The length of teaching experience seemed to be influential in how teachers interacted with the FCM: those with long experience seemed to adapt and improvise more than the newly graduated teachers:

Then there are some things I don't agree with, although I really like the material, but when I encounter some elements that don't suit my style, we do something else. (T2 - S1, 2012)

The classroom observations and the analyses of the video recordings confirm that the teachers generally employed the suggestions in the material to a great extent, but that they applied the ideas of the FCM in various ways and sometimes improvised with their own ideas.

Usability of the material. The teachers stressed highly the 'usability' of the material, compared to other materials they had experience of. This might also be a condition for using such new material initially. They found the FCM to be structured in a way that reduced their workload; for example, according to them it was easy to grasp and use the ideas in practice:

The teacher guide's very clear, a lot of material to copy, every section has two pages and two extra pages, exercise [homework], envelopes with concrete material... (Teacher at CM1, 2013)

...so if it was page 100 in the students' book it was page 100 in the teacher guide. It was easy to find things and easy to give a lesson. (T7 - S1, 2014)

Teachers also found that the concrete material provided in the students' textbooks considerably diminished their workload:

T6: And that there was concrete material for all children.

T2: Really brilliant, now I'm back again, copying and so on, number cards and..., very boring...hopeless! (Teachers - S1, 2014)

The results from the analysis of the teachers' responses to the questionnaire (CM2, 2014) confirm their satisfaction with the usability of the materials (Appendix 2).

\section{Views on mathematics education}

The second theme is related to the teachers' experiences of the FCM in relation to their views on mathematics education, namely on mathematical progression and learning mathematics, teaching methods and views of learning, and mathematical language and structure. These issues, emerging from different traditions, impacted the teachers' interplay with the material, especially those with more than three years of teaching experience. 
Progression. The teachers paid attention to the way mathematical content was presented as well as to the progress students were expected to make during a certain time period, such as a single lesson. At the collegial meetings, they compared the content with that of national examinations. The teachers pointed out that the expected progress was communicated clearly and seemed more demanding than what they were accustomed to. For example, the Grade 1 teachers cited the difference in number area and the use of number line:

we work... in the earlier books or like I usually work, we work a lot with a number line. But our number line, or the number line I start with, is the one that extends from zero to ten. Here, the number line extends from zero to 20 right away; in other words, the number line just goes on, do you understand? (T2 - S1, 2010)

The "ten transition", launched already in Grade 1, is another example of the differences teachers confronted when using the FCM. Most of them found the higher expectations to be a positive challenge. Hence, these teachers trusted that they could improve their students' performance by following the material. However, some of the experienced teachers saw the faster progression as a problem, believing it 'made students' learning difficulties visible already in Grade 1':

Several students think math is more difficult now than it used to be [in Grade 1]. (T11 - S3, 2012)

These teachers felt anxiety as they did not want the first-graders to experience failure caused by the more demanding mathematical content provided in the FCM.

View of learning and teaching methods. The teachers' earlier experiences of how students learn mathematics impacted their interplay with the FCM. For example, the mental strategies used for the ten-transition were different than those they were accustomed to. Swedish textbooks typically present a number of strategies connected to learning through number couples, for example $7+7=14$ and therefore $7+6=13$. Instead, the FCM shows the strategy of crossing over by completing first to a full ten, for example $7+6=7+3+3=10+3=13$.

The teachers in School 1 also brought up strategies related to partitions of numbers that are commonly applied in the number range from 0 to 20 in Swedish curriculum materials. Teachers stated that they had previously focused more on teaching addition tables:

I know we used to work a lot with addition tables from the beginning, I mean the combinations of the number 11, all of them, exactly like we did with number five, and so on in a similar manner with $12,13,14$, training all combinations, and they were drawing and so on like that, and I thought, 'Oh my goodness'. (T2 - S1, 2011)

Although teachers used the mental calculation strategies and mental arithmetic exercises applied in the FCM, they sometimes supplemented these with extra exercises-for instance, partitions of numbers in line with addition tables - and tried to combine the new strategies with something they were used to.

Early algebra provides another topic related to contradictions in views on mathematics education. There is a tradition in Swedish mathematics textbooks to include a large number of exercises, already starting in Grade 1, with multiple-choice 
answers, that show an understanding of the equal sign or pre-algebra, for example, $2+$ $={ }_{-}+6$. In the Finnish materials, the meaning of the equal sign $(=)$ is taught along with the signs for less than $(<)$ and greater than $(>)$ :

I usually start much earlier with open problems than the book does, [...] the equal sign and the meaning of it, where I feel that I work even more than I feel the book does in some way, so maybe this is wrong, because, still, I think the children aren't always confident with the meaning of the sign. (T1 - S1, 2011)

These differences caused the teachers some anxiety. For example, in the extract above Teacher 1 compares the different procedures and reflects on the possible effectiveness of her earlier procedures in relation to the new ones. She combined the previous set of exercises with those provided in the FCM to be on the safe side, because there was no rationale behind the suggestions in the FCM.

The teachers who reverted to the Swedish materials retained some ideas, for which they searched for material in the FCM; for example, lesson plans concerning a certain mathematical topic. In addition, they kept the concrete material included in the students' textbooks and continued using it to some extent with their students.

Mathematical language and structure. Several teachers paid attention to the way mathematics and relations between different mathematical concepts were communicated with a consistent use of mathematical terms. They considered this helpful in their work, for example, as it outlined connections between different mathematical content areas:

T10: Even clearer language, it's used all the time and helps them; they hear it in the stories that are also found on the website.

T12: Uses the correct terms and expressions, helps in seeing the mathematical connections; it builds one thing onto the other, the things come back.

(Teachers in S2 \& S3, summary discussion, 2013)

At the same time, some teachers (T11 and T12) stated that the FCM was more restrictive than the Swedish materials - no section could be skipped, as new knowledge often relied on the content previously introduced and focused on.

\section{Lesson scripts and pedagogical flow}

The last part of the results focuses on the issues related to how the different teaching cultures are confronted, especially regarding various elements of the lesson, lesson scripts and patterns in lesson sequences identified in the two countries as well as how much the teachers also seemed to change their practice after giving up the FCM.

Considering different learners. The teachers experienced that the structure of the material, namely setting learning goals for every lesson, differs from the Swedish materials, where the mathematical progress is not as clearly explicated. The FCM supports an instruction in which all students focus on the same lesson topic with differentiation (considering different learners) through various tasks and activities provided during each lesson.

In general, teachers mentioned their willingness to focus on the same mathematical area with the whole class instead of using speed individualization and, 
contrary to their previous practice, students were not allowed to proceed at their own pace with the textbook. This was also the case with the teachers at the second collegial meeting (CM2, 2014) (Appendix 2).

The teachers stated that there was much less competition in their classes when they worked in this manner, and this was viewed as positive. However, the change caused complaints from some parents and put pressure on teachers who felt anxious (cases T8 and T9). Confrontation was stronger in the later school years (Grades 3 and 4), when certain routines had already been established.

Most teachers perceived the idea of choosing from basic and additional problems provided for every lesson; that is, instead of every student completing all tasks, a teacher should select the appropriate activities for the whole class, different groups, and even individual students. For example, differentiation was organized through selecting different tasks and grouping students:

....and then that the quick students could move on to the extra pages while we all focused on this; this is what we're supposed to accomplish. (T6, S1, 2014)

We work like this, when they've completed the two pages, they take their math buddy with them and go outside the classroom and work on the pages, communicating with each other. They like co-operating on these pages a lot, and I think they talk a lot; 'do we have the math groups today?', they ask. They love these groups because they're able to complete the basic problems quickly in order to work on the next ones. (Teacher at CM1, 2013)

However, staying on certain lesson topics longer than planned, or returning to former pages with the whole group to ensure that all students were on track took place. Moreover, one teacher (T10) even wanted to implement all the activities of the FCM and therefore could not progress in the way initially planned.

After the first term, there were cases of going back to speed individualization, i.e. letting students proceed at their own pace, as is typical for the Swedish materials, as a better option for making it easier for students who struggled with the content. Moreover, some substitute teachers allowed students to proceed at their own pace, without selecting tasks for different students or introducing students to a new topic through common activities and instruction, as suggested in the FCM teacher guide. This led to a situation in which the students had progressed at very different rates through the textbook when their regular teacher returned (cases T4 and T8).

New lesson events. The teachers closely followed the ideas presented in the material and adopted new activities, such as small mental arithmetic exercises, elaborations with concrete materials, storytelling, and homework assignments:

We discussed the picture, and they listened to the story; we did what we were to do, and then they had this small square [homework] that they took home. (T6 - S1, 2014)

Our initial investigations with the pre-questionnaire (Appendix 1) showed that contrary to the Finnish tradition, assigning homework after every lesson was not common before starting to use the FCM. If they had assigned homework at all, it typically involved a weekly task: 
Although we have another kind of reasoning here in our school, we're moving more toward a kind of weekly homework that should be something that engages the whole family... (T1 - S1, 2010)

Teachers wanted to assign homework regularly to their students following the idea of the FCM, but were afraid students would leave their textbooks at home. Nevertheless, it was possible to establish a new habit with the first-graders by telling them 'the textbook lives in your school bag'. These teachers were satisfied with this, as taking the textbook home also allowed the students to work at home when they were sick. In addition, extra materials such as audio files on the website allowed students to take part in activities similar to those used in their class at school:

They do it at home, they have the book in their bag, and they log in and listen. (T11 - S3, 2012)

This was not the case for the teachers who received little additional information about the rationale behind the FCM. The responses of the teachers at the collegial meeting (CM2, 2014) show that the Finnish tradition of assigning homework was implemented only partially (Appendix 2).

Teachers faced the confrontation of different educational traditions also through the feedback given by parents. Parents, especially those with a school background from a different country than Sweden, were satisfied with daily homework, according to the teachers, as it allowed them to follow closely what their children were learning in school. However, some Swedish parents demanded to have homework assignments only on certain occasions, preferably weekends, due to other activities during the week such as time-consuming hobbies. This caused anxiety among the teachers, some of whom had difficulty resisting the pressure.

Several activities the teachers carried out in the classroom when interacting with the FCM vanished from their everyday practice when they reverted to using the Swedish materials. This was the case even though teachers were willing to change their practice, for example, in terms of expected student progression and testing new teaching methods and activities in mathematics. For example, they seldom organized short mental arithmetic exercises followed by whole-class discussions, as they had done previously:

T7: I still miss certain elements like those mental calculation squares, and that's something the children still ask about [...] They really thought they were fun. But now it just doesn't happen, because you're not reminded of them...

T6: I've given that up totally; it's seldom you remember, 'now let's do some mental arithmetic'. (Teachers - S1, 2014)

However, the teachers retained some ideas, for which they searched for material in the FCM; for example, lesson plans concerning a certain mathematical topic. In addition, they kept the concrete material included in the students' textbooks and continued using it to some extent with their students.

Assessment. Both the small assignment of homework and the specific mental arithmetic exercises were used by the teachers in our study to assess students' progress and to allow the students to perform self-assessment. The teachers also regularly used ready- 
made written tests, which are designed to help teachers continuously follow student learning:

.... and these tests, too, diagnoses after every [sequence of lessons], so you see if the students have learnt the topics we’ve worked with. (T6 - S1, 2014)

According to the analysis of the teachers' responses to the pre-questionnaire (Appendix 1), it was usual for the teachers to gather their students' textbooks about once a week or more seldom to correct the tasks. Many teachers in Schools 1-3 regularly let their students check the correctness of their solutions, for example together with other students, starting already in Grade 1, in accordance with the Finnish tradition. This was not the case for the teachers participating in the collegial meeting (CM2, 2014), who had not received any additional information about the Finnish tradition. Among these teachers, it was rare to let students check their solutions themselves (Appendix 2). Most of these teachers followed the typical Swedish tradition of the teacher checking and correcting the students' solutions.

\section{Discussion}

All the teachers in our study examined the FCM carefully, and most of them used the materials in a literal manner (cf. Brown, 2009), following it as closely as possible, at least in the beginning. Teachers also based their year and lesson plans on the specific flow of lessons and lesson events in the materials (cf. Andrews, 2007). In Brown's (2009) terms, they 'offloaded' a large degree of agency for guiding instructional activity onto the materials, and showed no signs of guilt in doing this (cf. Pehkonen, 2007). One reason for this could be that the teachers had voluntarily started working with the materials, and felt that by relying on it they would be able to reform their own practice. Hence, although they surrendered some agency to the materials, a great deal of their professional agency was focused on changing their teaching, bearing in mind the poor results of national and international evaluations and the many criticisms targeting the common working approaches in Swedish mathematics classrooms (e.g. Boesen et al., 2014). As the change they had made was based on their own choice, instead of guilt they showed satisfaction with what they had accomplished.

Indeed, the teachers were open to new ways of working, and there were no externally imposed expectations on them (cf. Vandenberghe, 2002). It is possible that the good results of Finnish students in international comparisons added some extra authority to the materials and the working practice they promote, even if the teachers lacked evidence of their students' future results (cf. Guskey, 2002). Relying closely on the material was also a way for the teachers to get to know it better.

The interplay between the Swedish teachers and the FCM was also influenced by the specific character of the materials (cf. Kauffmann, 2002; Brown, 2009), and the notions of offloading, adapting, and improvising (Brown, 2009) must be recontextualized to the specific features of the FCM. For example, the material is not created in a linear manner like a manuscript of instruction on how lessons should proceed, as is the case with several US materials (Brown, 2009). Rather, the FCM is created as a map, with a variety of suggested activities connected to a central learning goal and lesson topic (Hemmi et al., 2017). Teacher professionalism comes into play when a teacher selects and implements the relevant activities for individual students/groups of students/the whole class when designing and enacting a lesson. This means that the teachers who used the materials in a meaningful manner did not offload their entire professional agency to them, even though they did not use other resources. 
Rather, there was a kind of adaption process when choosing and applying various ideas in classroom practice according to the teachers' professional judgment. As our observations of lessons indicate, this could happen in several different ways.

The consistent use of mathematical terms and the clear presentation in the FCM revealing mathematical connections were experienced as positive by the teachers in our study. It is possible that the heavy emphasis in the Swedish curriculum on everyday mathematics (Hemmi, Lepik \& Viholainen, 2013; Hemmi \& Ryve, 2015b) has led to the production of materials that do not stress the proper use of mathematical terminology (cf. Herbel-Eisenmann, 2009), and therefore the teachers perceived this emphasis to be especially helpful. Moreover, earlier studies show that, contrary to the Swedish national curriculum, the Finnish national curriculum stresses students' understanding of mathematical connections from the early grades (Hemmi, Lepik \& Viholainen, 2013). Still, some teachers experienced that the presentation of mathematics restricted their possibilities to improvise and adapt the material, because it was difficult to change the order or skip certain core content of the materials as they had previously been able to do with the Swedish materials.

Previous research shows that there are great differences regarding the ways teachers adapt new ideas from curriculum materials and succeed in developing their teaching (e.g. Collopy, 2003; Remillard \& Bryans, 2004). Remillard and Bryans (2004) suggest that inexperienced teachers are most likely to fully utilize all the reform-based curriculum resources, and our study confirms this result to some extent. Although the teachers followed the materials carefully, especially those with long experience improvised in a specific way by blending different traditions of mathematical content and methods in their interplay with the materials. This is connected to the teachers' views on and experiences of the instructional effectiveness of the materials (see efficacy in Kauffmann, 2002; anxiety in Christou et al., 2009). In line with the teachers in the study by Kauffmann et al. (2002), those in our study worried about the materials' compatibility with national tests. All the teachers with some years of teaching experience identified the higher expectations on students' progression in the FCM, and initially expected that the materials would help them improve their teaching and the students' learning. However, abandoning their earlier practices made them feel anxious, for example, when skills training with addition tables; thus, they added these kinds of exercises to their teaching to be on the safe side. Similar behavior has been also identified by Guskey (2002). A couple of teachers adapted the activities and improvised with no discernible reason. Obviously, they did not always feel like autonomous professionals if they followed the guide's instructions too closely instead of using their own creativity (cf. Ball \& Cohen, 1996).

Traditions regarding the organization of instruction with respect to differentiation, assessment, and homework seem to be critical for teachers' fruitful interplay with the FCM. This is natural, since in the Swedish classroom context it has traditionally been important to be sensitive to students and respect their 'maturity' by allowing them to proceed at an individual pace (Hemmi \& Ryve, 2015b). However, these teachers did not verify how many students were failing to keep up, and for this reason the whole class repeated the same content. Obviously, many teachers lacked both the personal and material resources to continuously offer support to struggling students while moving forward according to the initial planning, which is a common approach in Finnish mathematics classrooms. On the contrary, some Swedish teachers found it disturbing that students' difficulties were visible as early as in the first term. The way the Swedish publishing house adapted the materials, for example, omitting many demanding tasks and supporting materials, reflects the Swedish teaching tradition. The 
problems cannot be very demanding if a teacher needs to be able to individually coach students who are working at different levels. Also, supporting struggling students and trying to keep them on track demands relevant tools, which the teachers obviously lacked.

The instructional reality within a school community also has an impact on the way teachers interact with the materials (Stein \& Kim, 2009; McClain et al., 2009), and parents can be influential in textbook adaptations (Herbel-Eisenmann et al., 2006). Indeed, some teachers felt anxious due to parents who resisted the new ways of organizing the instruction, with respect to both the homework and keeping the students within the same topic area. Further, it was difficult for substitute teachers to organize their teaching in a new manner because the instructional reality within the school community followed the current Swedish tradition.

One aspect the teachers strongly ascribed to the FCM was its ease of use (Kauffmann, 2002; Christou et al., 2009). In Sweden, it is commonly known that primary teachers' workload has increased in recent decades; hence, it could be 'acceptable' for teachers to talk about the issue of ease. Ease is also a consequence of relying only on one set of materials instead of searching for several other resources, as many of the teachers in our study had previously done when planning their teaching. Moreover, many activities in the teacher guides are described explicitly, which could offer important support for inexperienced teachers or those with a weak teacher education background in mathematics (cf. Stein \& Kim, 2009). When the teachers in School 1 reverted to the Swedish materials, they discarded several of the new features they had adopted but revisited the Finnish teacher guide to look for ideas for designing lessons focused on specific content. Thus, the teachers had acquired new knowledge about the resources, which allowed them to improvise with the new Swedish materials they had started using again.

\section{Conclusion}

Finally, in the light of the results of this study, we discuss some general aspects that we find important to consider when importing materials and ideas from other educationalcultural contexts.

First, it seems important to be aware of the factors that affect teachers' use of curriculum materials in general in certain educational-cultural contexts. For example, in the Swedish context, the teachers discussed the conflicts that emerge with some parents with strong expectations but there was no anxiety concerning the pressure of national tests and the correspondence of the materials with the national steering documents (cf. Christou et al. 2009).

Second, teachers' initial views on the effectiveness of the materials and the ease with which suggested ideas can be adopted in practice, as well as teachers' willingness to improve their teaching in accordance with the connected instructions (Kauffmann, 2002; Christou et al., 2009), are important for a successful interplay with new materials. In our study, all these premises were initially met, and the teachers managed to change their teaching by incorporating new working practices into their mathematics classrooms. An ease of access of the different tools connected to the material that harmonized with the planned reorganization of practices was crucial for the change these teachers accomplished (cf. Cobb \& Jackson, 2012).

The most important contribution of our study concerns the influence of rationale, or rather the lack thereof, on a fruitful interplay with new curriculum materials. According to several researchers, offering clear rationales for suggested activities or procedures is critical to teacher change (Davis \& Krajcik, 2005; Brown, 
2009). If there is no justification for certain working approaches in the materials, teachers continue with their previous routines to be on the safe side (cf. Guskey, 2002). But this is not enough in cross-cultural settings. The teachers in our study received minimal information about the Finnish classroom culture - some of them no information at all - before collegial meetings. The organization and content of the materials are presumably taken for granted in the countries where they are produced. Therefore, not much attention is paid to them. It is also possible that the lack of a rationale behind the recurring classroom activities in the FCM negatively impacted the teachers' change in the long term, as they did not consider them worth utilizing without the support of the material.

Finally, there are parallels between this study and the issue of teacher change in the context of curriculum reform, as the expected changes have often been planned and developed by actors outside the ordinary schools. Therefore, in our view, our study raises critical issues connected to the production and implementation of reform curriculum materials that challenge the existing school culture. The role of teachers, and the surrounding community's shared knowledge about the rationale behind the new ideas provided in materials seems to be crucial and, thus, should be explored and developed in more detail in further studies.

\section{References}

Andrews, P. (2007). The curricular importance of mathematics: A comparison of English and Hungarian teachers' espoused beliefs. Journal of Curriculum Studies, 39, 317-338. doi:10.1080/00220270600773082

Ball, D. L., \& Cohen, D. K. (1996). Reform by the book: What is: or might be: the role of curriculum materials in teacher learning and instructional reform? Educational Researcher, 25(9), 6-14. doi:10.3102/0013189x025009006

Braun, V., \& Clarke, V. (2006). Using thematic analysis in psychology. Qualitative research in psychology, 3(2), 77-101.

Clarke, D. (2013). The Validity-Comparability Compromise in Cross-cultural Studies in Mathematics Education. In B. Ubuz, Ç. Haser, \& M. A. Mariotti (Eds.), The Proceedings of the Eighth Conference of the European Society for Research in Mathematics Education - CERME-8, Middle East Technical University, Ankara.

Cohen, D. (1990). A Revolution in One Classroom: The Case of Mrs. Oublier. Educational Evaluation and Policy Analysis, 12(3), 311-329.

Boesen, J., Helenius, O., Bergqvist, E., Bergqvist, T., Lithner, J., Palm, T., \& Palmberg, B. (2014). Developing mathematical competence: From the intended to the enacted curriculum. The Journal of Mathematical Behavior, 33, 72-87. doi:10.1016/j.jmathb.2013.10.001

Brown, M. W. (2009). The teacher-tool relationship: Theorizing the design and use of curriculum materials. In J. Remillard, B. Herbel-Eisenmann, \& G. Lloyd (Eds.), Mathematics teachers at work: Connecting curriculum materials and classroom instruction (pp. 17-36). New York: Routledge.

Christou, C., Eliophotou Menon, M., \& Philippou, G. (2009). Beginning teachers' concerns regarding the adoption of new mathematics curriculum materials. In J. Remillard, B. Herbel-Eisenmann, \& G. Lloyd (Eds.), Mathematics teachers at work: Connecting curriculum materials and classroom instruction (pp. 223-244). New York: Routledge.

Cobb, P., \& Jackson, K. (2012). Analyzing educational policies: A learning design perspective. Journal of the Learning Sciences, 21,487-521. doi:10.1080/10508406.2011.630849 
Collopy, R. (2003). Curriculum materials as a professional development tool: How a mathematics textbook affected two teachers' learning. The Elementary School Journal, 103, 287-311. doi:10.1086/499727

Davis, E. A., \& Krajcik, J. S. (2005). Designing educative curriculum materials to promote teacher learning. Educational Researcher, 34(3), 3-14. doi:10.3102/0013189x034003003

Guskey, T. R. (2002). Professional development and teacher change. Teachers and Teaching, 8, 381-391. doi: 10.1080/135406002100000512

Hemmi, K., Krzywacki. H., \& Koljonen, T. (2017). Investigating Finnish Teacher Guides as a Resource for Mathematics Teaching. Scandinavian Journal of Educational Research, 1-18. doi:10.1080/00313831.2017.1307278

Hemmi, K., Lepik, M., \& Viholainen, A. (2013). Analysing proof-related competences in Estonian, Finnish and Swedish mathematics curricula - towards a framework of developmental proof. Journal of Curriculum Studies, 45, 354-378. doi:10.1080/00220272.2012.754055

Hemmi, K., Koljonen, T., Hoelgaard, L., Ahl, L., \& Ryve, A. (2013). Analyzing mathematics curriculum materials in Sweden and in Finland: Developing an analytical tool. In B. Ubuz, Ç. Haser, \& M. A. Mariotti (Eds.), The Proceedings of the Eighth Conference of the European Society for Research in Mathematics Education - CERME-8, Middle East Technical University, Ankara.

Hemmi, K., \& Krzywacki, H. (2014). Crossing the boundaries: Swedish teachers' interplay with Finnish curriculum materials. In Jones, K., Bokhove, C., Howson, G., \& Fan, L. (eds.). Proceedings of the International Conference on Mathematics Textbook Research and Development (ICMT-2014), (pp. 263-268). Southampton, GB, University of Southampton.

Hemmi, K., \& Ryve, A. (2015a). The culture of the mathematics classroom during the first school years in Finland and Sweden. In B. Perry, A. MacDonald, \& A. Gervasoni (Eds.), Mathematics and transition to school - International perspectives (pp. 185-198). Singapore: Springer.

Hemmi, K., \& Ryve, A. (2015b). Effective mathematics teaching in Finnish and Swedish teacher education discourses. Journal of Mathematics Teacher Education, 18, 501-521. doi:10.1007/s10857-014-9293-4

Herbel-Eisenmann, B. A. (2009). Negotiating the 'Presence of the text' - How might teachers' language choices influence the positioning of the textbook. In J. Remillard, B. Herbel-Eisenmann, \& G. Lloyd (Eds.), Mathematics teachers at work: Connecting curriculum materials and classroom instruction (pp. 134-151). New York: Routledge.

Herbel-Eisenmann, B. A., Lubienski, S. T., \& Id-Deen, L. (2006). Reconsidering the study of mathematics instructional practices: The importance of curricular context in understanding local and global teacher change. Journal of Mathematics Teacher Education, 9(4), 313-345.

Hill, H. C., \& Charalambous, C. Y. (2012). Teacher knowledge, curriculum materials, and quality of instruction: Lessons learned and open issues. Journal of Curriculum Studies, 44, 559-576. doi:10.1080/00220272.2012.716978

Jablonka, E., \& Johansson, M. (2010). Using texts and tasks. In Sriraman, B., Bergsten, C., Goodchild, S., Palsdottir, G., Søndergaard, B.D., \& Haapasalo, L. (Eds.). The sourcebook on Nordic research in mathematics education. Charlotte, NC: Information Age Publishing, 363-372. 
Kauffmann, D. (2002, April). A search for support: Beginning elementary teachers' use of mathematics curriculum materials. Paper presented at the Annual Meeting of the American Educational Research Association, New Orleans, LA.

Leder, G. C., Pehkonen, E., \& Törner, G. (Eds.). (2002). Beliefs: A hidden variable in mathematics education? Dordrecht: Kluwer Academic Publishers.

McClain, K., Zhao, Q., Visnovska, J., \& Bowen, E. (2009). Understanding the role of the institutional context in the relationship between teachers and text. In J. Remillard, B. Herbel-Eisenmann, \& G. Lloyd (Eds.), Mathematics teachers at work: Connecting curriculum materials and classroom instruction (pp. 56-69). New York: Routledge.

Miles, M. B., \& Huberman, A. M. (1994). Qualitative data analysis (2 ${ }^{\text {nd }}$ edition). Thousand Oaks: Sage Publications.

OECD. (2013). PISA 2012 results in focus. What 15-year-olds know and what they can do with what they know. Retrieved from www.oecd.org/pisa

Pehkonen, L. (2007). To change or not to change - How primary school teachers speak about stability and change. Nordic Studies in Mathematics Education, 12(2), 5776.

Remillard, J. T. (2005). Examining key concepts in research on teachers' use of mathematics curricula. Review of Educational Research, 75, 211-246. doi:10.3102/00346543075002211

Remillard, J. T., \& Bryans, M. B. (2004). Teachers' orientations toward mathematics curriculum materials: Implications for teacher learning. Journal for Research in Mathematics Education, 35, 352-388. doi:10.2307/30034820

Ryve, A., \& Hemmi, K. (2017). Operationalizing educational policy in context: Using US-theories for improving mathematics instruction at scale in Sweden. Submitted to Educational Studies in Mathematics, Special issue: Scaling up innovative approaches to mathematics education.

Spillane, J. P. (1999). External reform initiatives and teachers' efforts to reconstruct their practice: The mediating role of teachers' zones of enactment. Journal of Curriculum Studies, 31, 143-175. doi:10.1080/002202799183205

Stein, M. K., \& Kim, G. (2009). The role of mathematics curriculum materials in largescale urban reform. In J. Remillard, B. Herbel-Eisenmann, \& G. Lloyd (Eds.), Mathematics teachers at work: Connecting curriculum materials and classroom instruction (pp. 37-53). New York: Routledge.

Stigler, J. W., \& Hiebert, J. (2000). The teaching gap: Best ideas from the world's teachers for improving education in the classroom. Journal of Curriculum Studies, 32, 867-874. doi:10.1080/00220270050167215

Stake, R. (2005). Qualitative case studies. In N. K. Denzin, \& Y. S. Lincoln (Eds.), Handbook of qualitative research (3rd edition) (pp. 443-446). Thousand Oaks: Sage Publications.

Taylor, M. W. (2013). Replacing the 'teacher-proof' curriculum with the 'curriculumproof' teacher: Toward more effective interactions with mathematics textbooks. Journal of Curriculum Studies, 45, 295-321. doi:10.1080/00220272.2012.710253

Vandenberghe, R. (2002). Teachers' professional development as a core of school improvement. International Journal of Educational Research, 37, 653-659. doi:10.1016/s0883-0355(03)00063-6

Wertsch, J. V. (1991). Voices of the mind: A sociocultural approach to mediated action. Cambridge, MA: Harvard University Press. 


\section{Appendix 1}

The questions in the pre-questionnaire on working practices and the relationship with

curriculum materials relevant for this study (translated from Swedish)

1. What grades are you teaching this year?

2. What do you think works well in your mathematics classrooms?

3. Is there something that causes problems?

4. Describe what a mathematics lesson is like when you teach.

5. If you give homework, please answer the following questions:

a) How often and why do you give homework?

b) How do you follow up the homework?

6. Does the textbook/teacher guide offer enough support for your teaching?

7. Do you use other sources for inspiration?

8. Do you correct tasks of the student textbook?

9. Do students correct the tasks themselves?

10. How do you individualize/differentiate mathematics teaching?

a) Students work with their textbooks at their own pace.

b) Different tasks are assigned to different student within the same mathematical area.

c) In some other way, how?

11. How often do you investigate student solutions with the whole class?

12. How often do you have mental arithmetic exercises done orally?

13. Which curriculum program do you use?

a) What aspects do you like in this program?

b) What makes you unsatisfied with the program?

14. What teacher guides do you use?

15. In what ways do teacher guides/textbooks help to vary and differentiate your teaching?

16. How do you evaluate student learning?

17. Finally, we would like to know about your teaching experience and educational background as a teacher 


\section{Appendix 2}

\section{Collegial meeting CM2}

\begin{tabular}{|c|c|c|c|c|c|c|}
\hline $\begin{array}{l}\text { Experience } \\
\text { Years }\end{array}$ & Teacher & Fidelity & Usability & Diff & HW & $\begin{array}{l}\text { Assessment } \\
\text { /Feedback }\end{array}$ \\
\hline \multirow[t]{5}{*}{$0-2$} & 1 & 2 & 2 & 1 & 0 & 0 \\
\hline & 2 & 2 & 2 & 2 & 2 & - \\
\hline & 3 & 1 & 2 & 1 & 2 & 0 \\
\hline & 4 & 3 & 2 & 1 & 0 & 3 \\
\hline & 5 & 2 & 2 & 1 & 0 & 0 \\
\hline \multirow[t]{3}{*}{$3-10$} & 6 & 3 & 3 & 1 & 0 & 3 \\
\hline & 7 & 2 & 3 & 1 & 1 & 0 \\
\hline & 8 & 3 & 3 & 2 & 1 & 2 \\
\hline \multirow[t]{4}{*}{$11-20$} & 9 & 2 & 3 & 2 & 2 & 0 \\
\hline & 10 & 2 & 3 & 2 & 1 & 0 \\
\hline & 11 & 3 & 3 & 2 & 2 & 0 \\
\hline & 12 & 2 & 2 & 1 & 0 & 0 \\
\hline \multirow[t]{5}{*}{$>20$} & 13 & 3 & 2 & 2 & 2 & 0 \\
\hline & 14 & 3 & 3 & 1 & 2 & 2 \\
\hline & 15 & 2 & 2 & 2 & 2 & 0 \\
\hline & 16 & 2 & 2 & 1 & 0 & 0 \\
\hline & 17 & 2 & 2 & 2 & 0 & 0 \\
\hline
\end{tabular}

Fidelity: 0 - Does not use the FCM; 1 - Uses some ideas; 2 - Follows, sometimes adapting and improvising; 3 - Follows literally

Usability: 0 - Negative; 1 - No opinion; 2 - Positive; 3 - Very positive

Diff (Differentiation): 0 - Students work at their own pace in different areas; 1 - Students work within the same area; 2 - Students work within the same area but can work with different tasks

HW (Homework): 0 - No homework; 1 - Homework for a week; 2 - Homework after each lesson Assessment (Checking the correctness of student solutions): 0 - Teacher; 1 - Sometimes teacher, sometimes students; 2 - Students; 3 - Teacher together with the class 